\title{
A Circular Polarized Rectenna with Out-of-Band Suppression for Microwave Power Transmission
}

\author{
Weijun Hong, ${ }^{1,2}$ Yanjie Cao, ${ }^{1,3}$ Li Deng, ${ }^{1,3}$ Shufang Li, ${ }^{1,3}$ Mengmeng Li, ${ }^{1,3}$ and Hongjie Liu ${ }^{2}$ \\ ${ }^{1}$ Beijing Key Laboratory of Network System Architecture and Convergence, Beijing, China \\ ${ }^{2}$ Beijing Advanced Innovation Center for Future Internet Technology, Beijing, China \\ ${ }^{3}$ Beijing Laboratory of Advanced Information Network, Beijing University of Posts and Telecommunications, Beijing, China
}

Correspondence should be addressed to Li Deng; dengl@bupt.edu.cn

Received 22 August 2016; Accepted 19 October 2016

Academic Editor: Ahmed T. Mobashsher

Copyright (C) 2016 Weijun Hong et al. This is an open access article distributed under the Creative Commons Attribution License, which permits unrestricted use, distribution, and reproduction in any medium, provided the original work is properly cited.

\begin{abstract}
A novel circular polarized rectenna with out-of-band suppression is proposed in this paper. The circular polarization is realized by corner perturbation on a rectangular radiation patch and enhanced by a diagonal slim slot etched at the center of the patch. An open stub connecting to the quarter wavelength impedance transformer is used to suppress out-of-band wave through harmonics notching. The results of simulations and experiments agree very well, which show that the rectenna obtained $-19 \mathrm{~dB}$ return loss at $2.4 \mathrm{GHz}$ and $-15.5 \mathrm{~dB},-18.1 \mathrm{~dB}$, and $-11.4 \mathrm{~dB}$ suppression on second, third, and fourth harmonic frequency bands, respectively. The reflection coefficient in overall out-of-band, up to $10 \mathrm{GHz}$, is limited up to $-3 \mathrm{~dB}$. Integrated with a voltage doubling rectification circuit, the proposed rectenna can obtain $75.5 \%$ RF-to-DC conversion efficiency.
\end{abstract}

\section{Introduction}

In recent years, wireless power transmission (WPT) has become an intriguing solution for contactless powering of low power consuming electronic devices, such as wireless sensors and body area network devices [1]. WPT can be achieved by different approaches such as near-field inductive coupling [2], magnetic resonant coupling [3, 4], and microwave power transmission (MPT) [5-19]. Comparing with the previous two power transferring approaches, MPT exhibits significant advantages on the ability of energy transfer direction controlling and much longer transmission range. In MPT systems, the terminals are supposed to be driven by direct current (DC) voltage; thus, to power the terminal, the RF front end of the MPT should be followed by a rectification circuit which transfers the alternative voltage at microwave frequency from receiving antenna to DC voltage output. Beside the large size, issues on mechanical connection and impedance mismatching between the antenna and the rectifier would inevitably cause reduction on energy conversion efficiency of the system.

Rectenna is proposed as a solution for abovementioned problem, which acts as a microwave-to-dc power converter and is designed as a single device combing the functionality of receiving antenna and rectifier. Thus, the performance of rectenna has become one of the most important factors affecting the efficiency of MPT system. Traditional rectennas consist of a receiving antenna, a band-pass filter (BPF), a matching circuit, a rectifier, a low pass filter, and loads. The $\mathrm{BPF}$ is used for reflecting the harmonics generated by rectifier diodes due to their nonlinearity, therefore improving the efficiency of energy conversion. However, the general BPF has a large dimension and introduces nonnegligible insertion loss.

Recent researches on rectenna proposed several methods to enhance power collection and conversion efficiency. The authors in [7-9] proposed multiband antennas to broaden the frequency band of power collection, which simultaneously raises difficulties on design of matching circuit. The authors in $[10,11]$ used antenna array to increase the gain of the receiver at particular receiving direction, which enlarged the overall size to times of single antenna and significantly increased the requirements on radiation pattern alignment between receiving antenna and the source. In [12-15], combinations of antenna and harmonic suppression filter were proposed to suppress the out-of-band signal; however, their structures are 


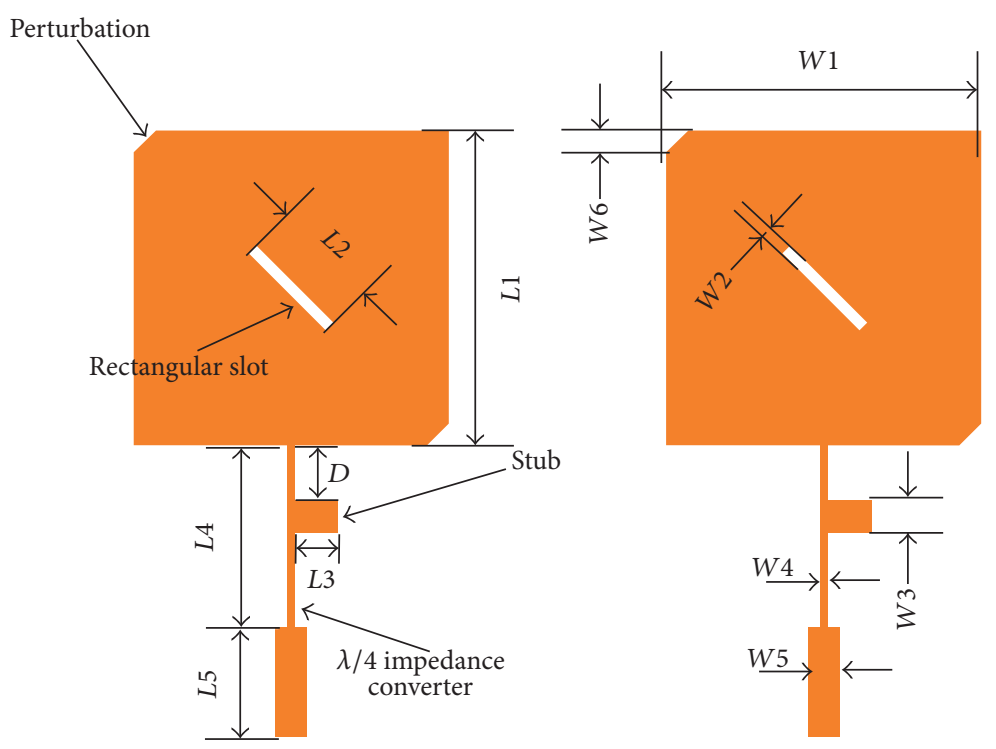

FIGURE 1: The layout of antenna part of proposed rectenna.

so complicated that they highly impact the power collection efficiency of the receiving antenna.

A novel high efficiency rectenna with out-of-band suppression is proposed in this paper, which has two significant advantages: first, circular polarization is used to minimize the polarization mismatch to linear polarized transmitter; second, an open stub on transmission line and fan-shaped printed circuit instead of conventional BPF is designed to suppress harmonics at front-end and backend which finally alleviate out-of-band fluctuation. The performance of two types of filtering structure, single branch and double branch, is studied in this paper, and the previous one is finally adopted in the proposed rectenna. The rest of this paper is organized as follows. Section 2 presents the design of rectenna including the design of circular polarized antenna and rectification circuit. Section 3 shows the results of simulations and experiments. Finally, conclusions are drawn in Section 4.

\section{Rectenna Design}

2.1. Antenna. Figure 1 shows the antenna part of proposed rectenna. The configurations of corresponding parameters are listed in Table 1. The length of the patch is quarter wavelength which can be calculated by

$$
L=\frac{1}{4 f \sqrt{\varepsilon_{0} \mu_{0}\left(1+\varepsilon_{r}\right) / 2}},
$$

where $f$ is the resonant frequency of antenna, $\varepsilon_{0}$ and $\mu_{0}$ are the permittivity and permeability of air, respectively, and $\varepsilon_{r}$ is the relative permittivity of substrate.

The substrate of the proposed antenna is FR4, which has $1.5 \mathrm{~mm}$ thickness with dielectric constant of 4.4. The methods of slotting and corner perturbation are used to realize the circular polarization. A $4 \mathrm{~mm} * 3 \mathrm{~mm}$ stub connected to the quarter wave length impedance converter is used to suppress
TABLE 1: Dimensions of proposed antenna.

\begin{tabular}{lc}
\hline Parameter & Value $/ \mathrm{mm}$ \\
\hline L1 & 28.9 \\
L2 & 8.4 \\
L3 & 4.0 \\
L4 & 16.8 \\
L5 & 10.0 \\
$D$ & 5.0 \\
$W 1$ & 28.9 \\
$W 2$ & 0.4 \\
$W 3$ & 3.0 \\
$W 4$ & 0.6 \\
W5 & 2.9 \\
W6 & 2.0 \\
\hline
\end{tabular}

the harmonics at the higher order modes. The stub works as a half wavelength open circuit resonator whose length is about half wavelength of the second harmonics. The quarter wave length impedance transformer is used to match the input impedance of radiation patch to $50 \Omega$ input port.

2.2. Rectification Circuit. We adopt the classical voltage doubling rectification circuit, Greinacher circuit, in the design. The circuit consisted of a $100 \mathrm{pF}$ capacity cascaded with a ring composed of two Schottky diodes HSMS2862 and one $100 \mathrm{pF}$ capacitor, as shown in Figures 2 and 3. As introduced in [16], HSMS2862 has a threshold voltage level of $650 \mathrm{mV}$, internal resistance of $6 \Omega$, and a breakdown voltage of $7 \mathrm{~V}$ and can work well up to $5.8 \mathrm{GHz}$. To reduce the high frequency fluctuation on output wave, a bypass capacitor would generally be used after the rectifier to conduct the alternating component to ground that would definitely cause power loss. Actually, the alternating signals in output wave are 


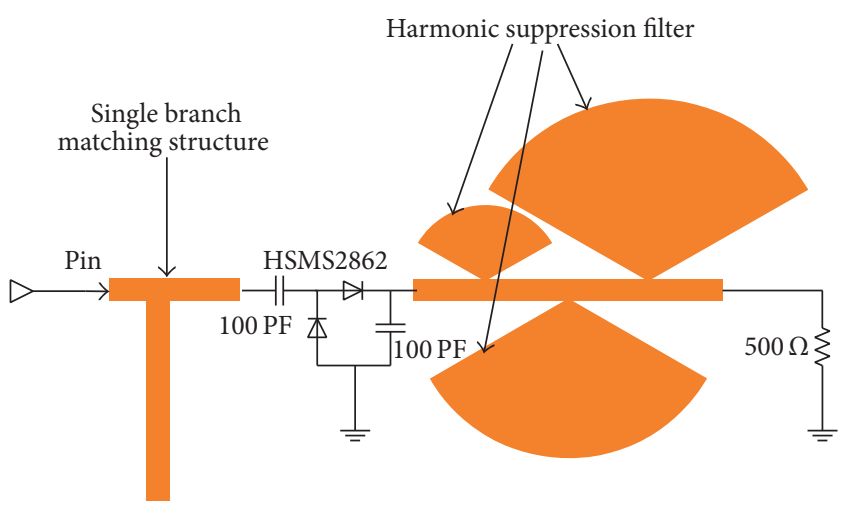

FIGURE 2: The layout of single branch structure cascaded with rectification circuit and fan-shaped filtering structure.

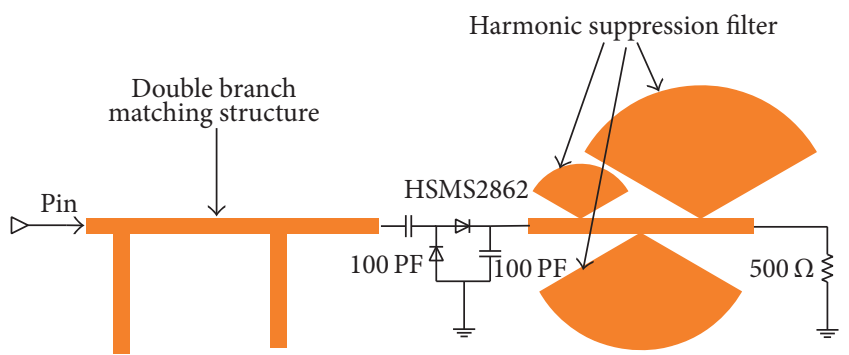

FIGURE 3: The layout of double branch structure cascaded with rectification circuit and fan-shaped filtering structure.

harmonic waves caused by the nonlinearity of diode. In this paper, we designed a printable fan-shape filtering structure to replace the low pass filter. The fan-shaped filtering structure can reflect the harmonics back to the rectification circuit, and these signals would partly be rectified to DC signal output; thus, the power transfer efficiency can be improved.

As is known, the input impedance of Schottky diode varies with the input power that would cause issues of impedance mismatch between the antenna and the backend circuit with different receiving signal strength of antenna. In MPT systems, the terminal devices are probably in a state of motion during wireless charging process; thus, it is a great challenge on design of impedance match circuit. We proposed two impedance match structures here, single branch matching structure (SBS) as shown in Figure 2 and double branch matching structure (DBS) as shown in Figure 3, and tested their performance in Section 3.

\section{Results and Discussion}

3.1. Performance of Antenna. Figure 4 shows the frequency behavior of the antenna reflection coefficient for antenna with and without slot. From the figure, we can see that slot in the center of radiation patch of the antenna can significantly improve the return loss at antenna resonant frequency $2.4 \mathrm{GHz}$, although it does not provide any improvements in out-of-band. That is because the slot makes the reactance of proposed antenna approach $0 \Omega$ as shown in the circled part

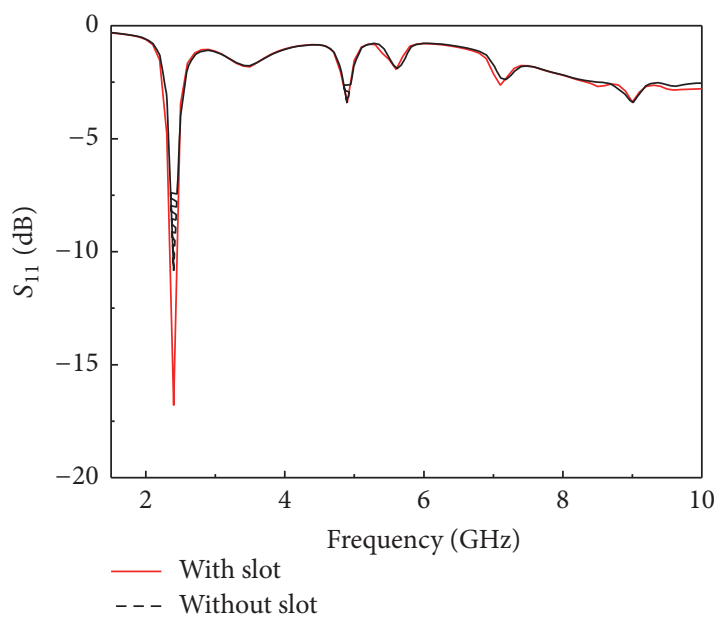

FIGURE 4: Simulated reflection coefficient characteristics for proposed antenna with and without slot.

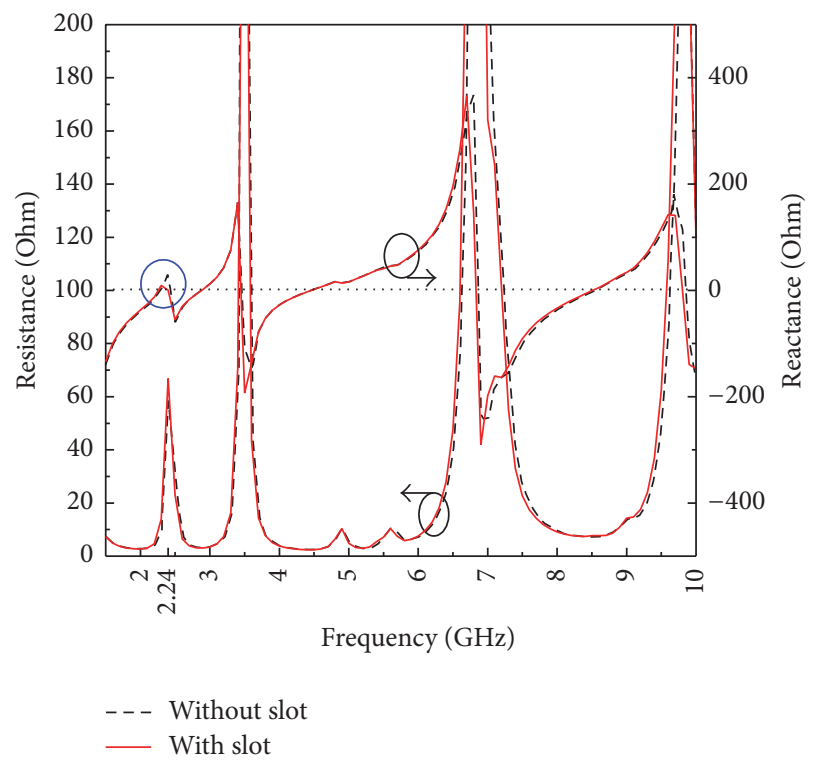

Figure 5: Simulated impedance for proposed antenna with and without slot.

of Figure 5, but barely with effect on other frequencies as well as on resistance of the antenna. Figure 6 shows more important functionality of slot on cross polarization enhancement. From Figure 6, it appears that the main polarization pattern of proposed antenna is left-hand circular polarization (LHCP), and the slot improves the cross polarization with $18.27 \mathrm{~dB}$, from $4.98 \mathrm{~dB}$ (without slot) to $23.25 \mathrm{~dB}$ (with slot).

Figure 7 shows the simulated $S_{11}$ of proposed antenna with and without stub. From the figure, we can see that the antenna without stub has four resonant frequencies at $2.2 \mathrm{GHz}, 4.9 \mathrm{GHz}, 6.1 \mathrm{GHz}$, and $9.2 \mathrm{GHz}$, with reflection coefficients $-9.29 \mathrm{~dB},-18.91 \mathrm{~dB},-21.59 \mathrm{~dB}$, and $-13.98 \mathrm{~dB}$, respectively. After adding the stub, the basic resonant frequency is tuned to $2.4 \mathrm{GHz}$ with $-18.28 \mathrm{~dB}$ reflection coefficient, and the reflection coefficient in all out-of-band is suppressed to greater than $-3 \mathrm{~dB}$. A prototype of the proposed antenna 


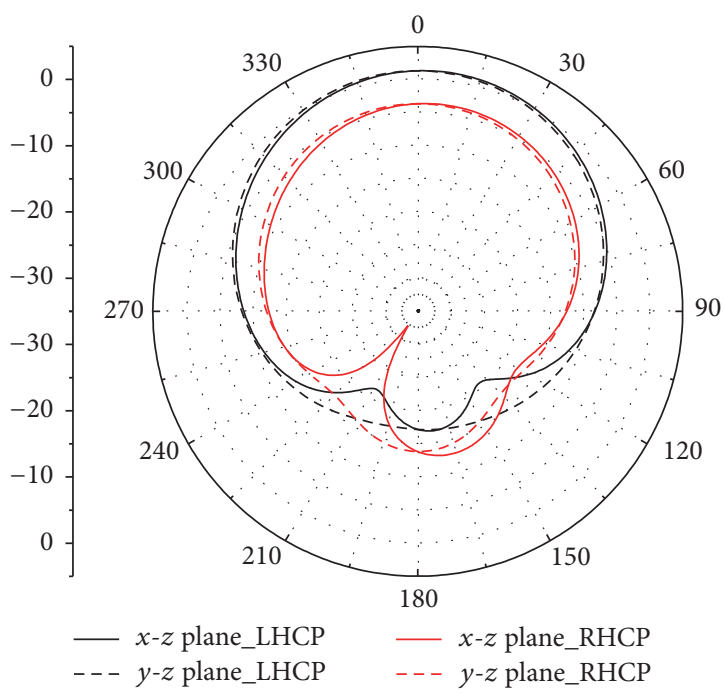

(a)

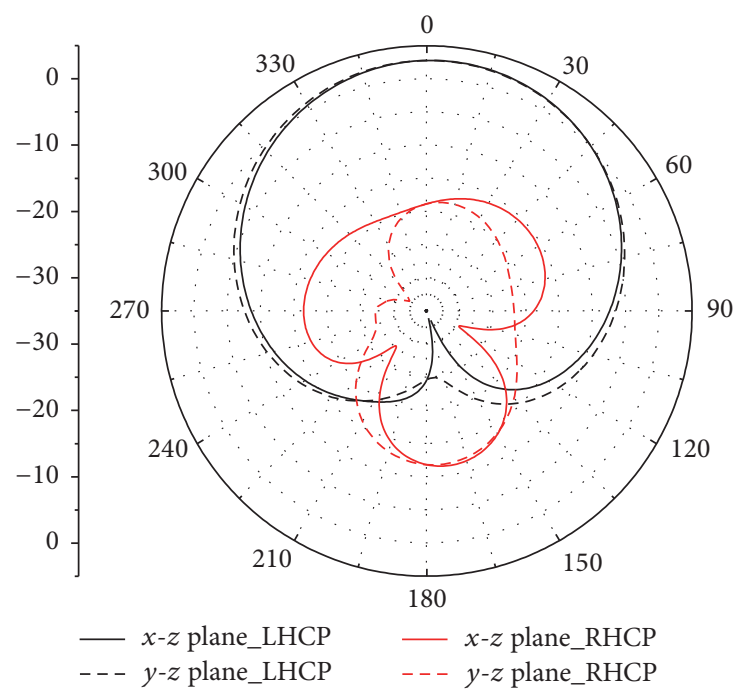

(b)

FIGURE 6: Radiation pattern of the antenna (a) without slot and (b) with slot.

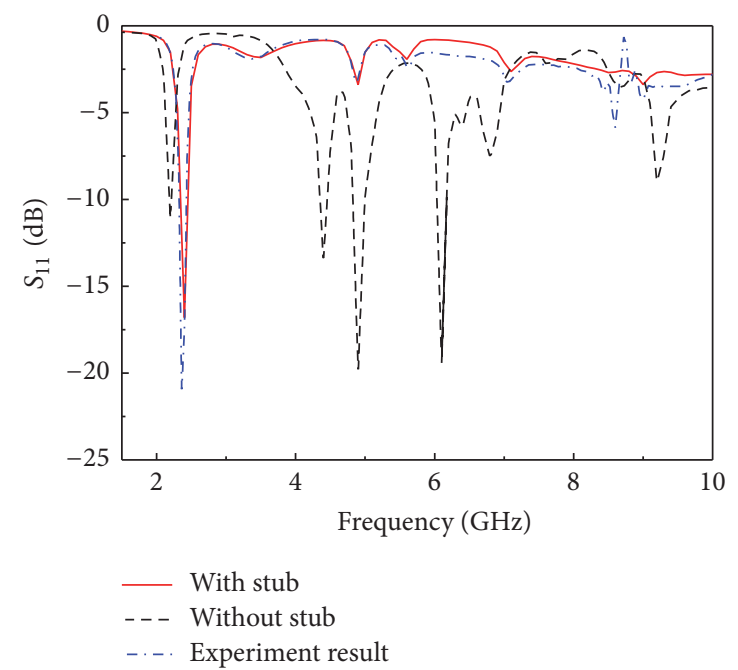

FIGURE 7: Simulated reflection coefficient for antenna with and without stub, and measured result of reflection coefficient of antenna.

is fabricated as shown in Figure 8. The measured reflection coefficient is plotted in Figure 7. We can see that the results of simulation and experiment match very well.

\subsection{Performance of Rectification Circuit. Performance of pro-} posed rectification circuit is simulated with software Agilent ADS. Figures 9 and 10 show that the input impedance of SBS and DBS varies with the input power, respectively. The resistance of DBS decreases dramatically when input power is greater than $20 \mathrm{dBm}$, while its reactance keeps steady at about $6 \Omega$, as shown in Figure 9. In contrast, the resistance of SBS increases obviously to about $100 \Omega$ at $28 \mathrm{dBm}$ input power and then decreases dramatically, and its reactance keeps increasing fast to about $155 \Omega$ with $40 \mathrm{dBm}$ input power.

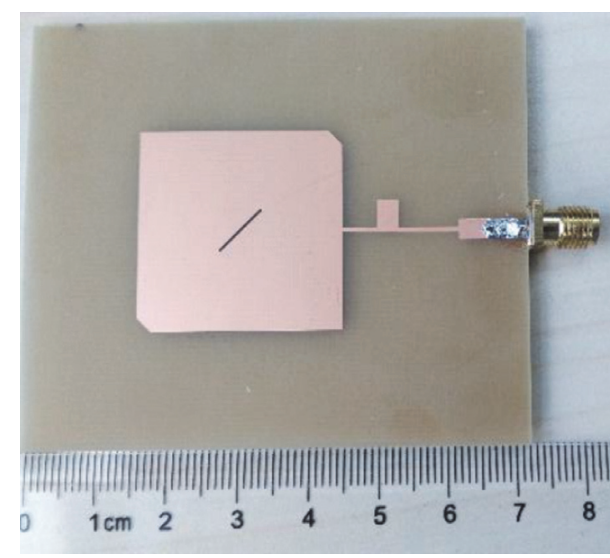

FIgURE 8: Prototype of the proposed antenna.

However, while under lower input power, $19 \mathrm{dBm}$ of SBS and $21 \mathrm{dBm}$ of DBS, the impedance curves of both structures are quite flat, which means that both structures can work well in ambient power collection which would probably be less than $20 \mathrm{dBm}$. From Figure 11, we can see that the proposed system can provide $5.45 \mathrm{~V}$ DC voltage with a $19 \mathrm{dBm}$ sinusoid wave input at $2.4 \mathrm{GHz}$, which is adequate for most portable devices, such as wireless sensors and body area network devices, even mobile phones.

Figures 12 and 13 show the efficiency of SBS and DBS rectification circuits as function of input power. Figure 12 shows that the efficiency of SBS increases from $63 \%$ to $75.5 \%$ within the input power range from $10 \mathrm{dBm}$ to $19 \mathrm{dBm}$ and turns to decrease after input power beyond $19 \mathrm{dBm}$. The efficiency curve of DRC has similar trend as shown in Figure 13, but with different turning point at $20 \mathrm{dBm}$ with the highest efficiency of $50.4 \%$. 


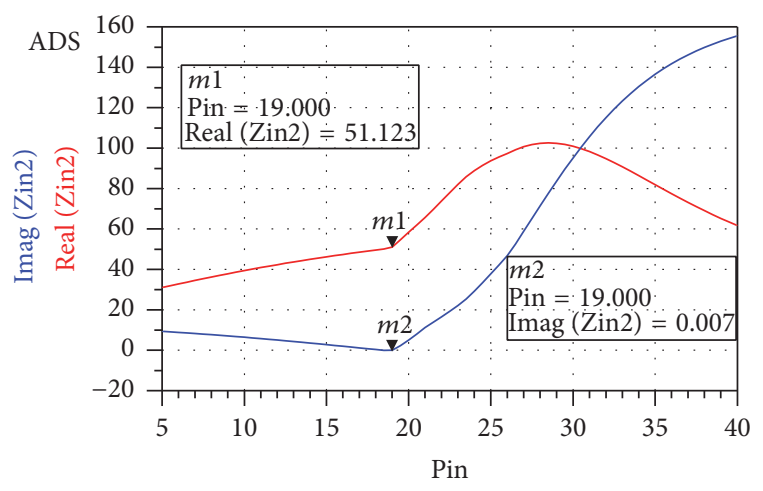

FIgURE 9: Input impedance of SBS.

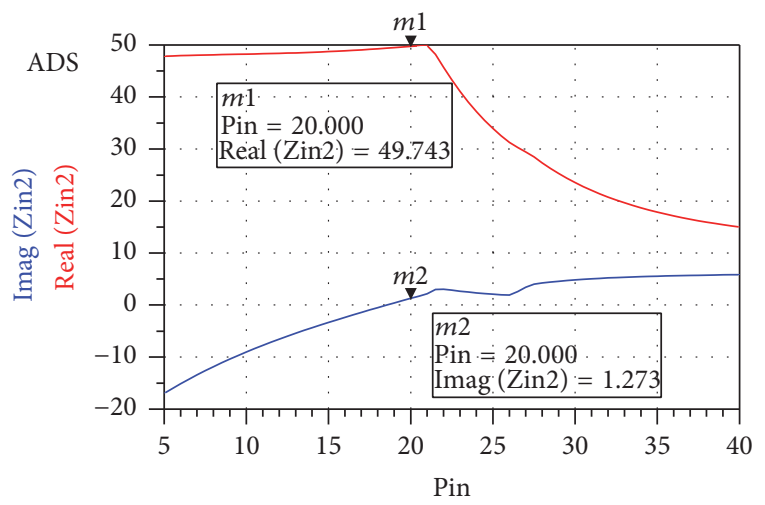

FIGURE 10: Input impedance of DBS.

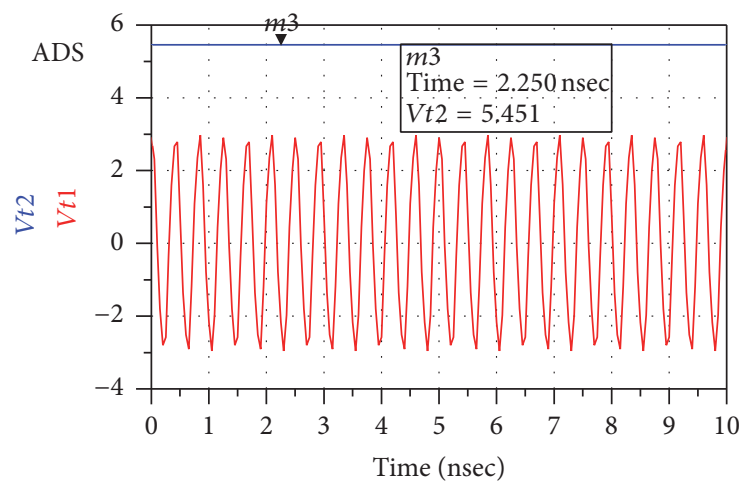

FIGURE 11: Output voltage of rectification circuit with $18 \mathrm{dBm}$ input sinusoidal wave.

By contrasting Figures 12 and 13, it appears that SBS outperforms DBS on efficiency; thus, we adopted SBS to be the rectification structure in our MPT system. The manufactured prototype of SBS is shown in Figure 14. We use a Universal Software Radio Peripheral (USRP) to generate the input signal for performance validation of the rectification circuit. The frequency and power of the signal generated by USRP can be feasibly adjusted by programming on development platform Labview. The output power of signal is calibrated by spectrum analyzer, as shown in Figure 15. The measurement process is shown in Figure 16; we connect the output port of

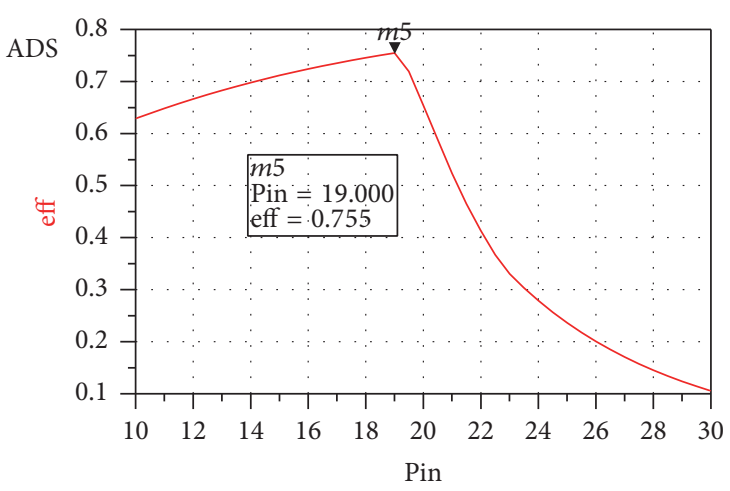

FIgURE 12: Efficiency of SBS.

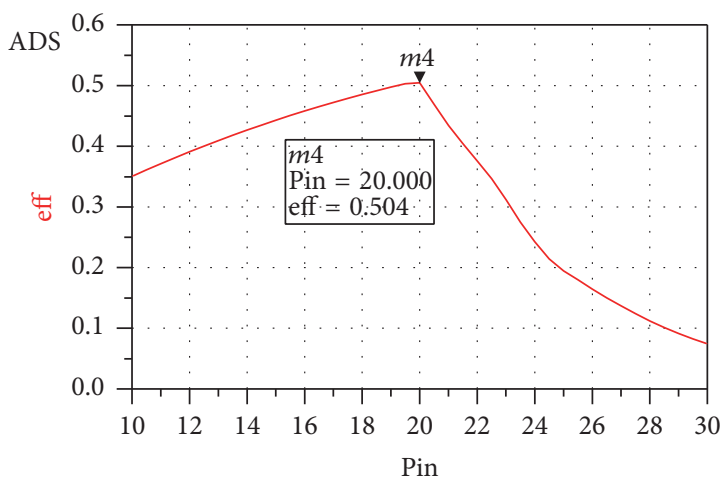

FIGURE 13: Efficiency of DBS.

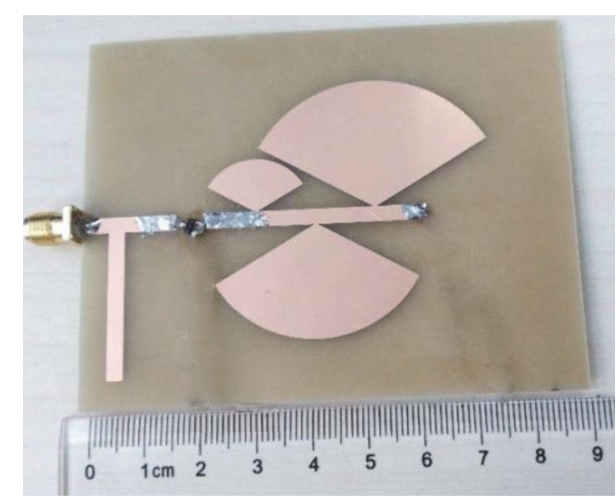

FIGURE 14: Prototype of the SBS rectification circuit.

USRP to SBS input port and use a AVO meter to measure the DC voltage at the output port. The measurement result agrees with the simulation result in Figure 11, and the deviation is only $0.2 \mathrm{~V}$.

In Table 2, the efficiency performance of the proposed rectenna is compared with those of some published rectenna designs. Obviously, the proposed rectenna is able to achieve good impedance matching and higher conversion efficiency than most of current designs. 


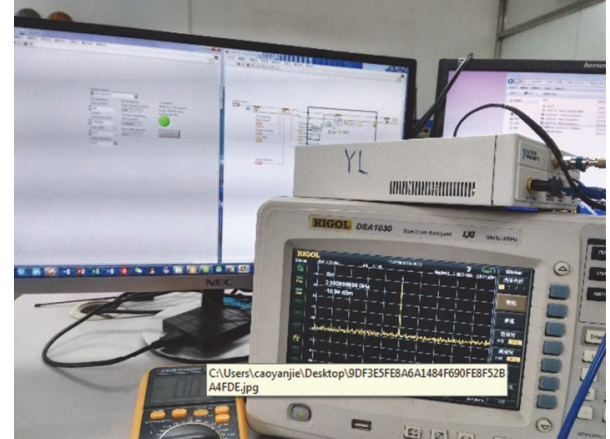

FIGURE 15: Experimental setups: an USRP is used to generate signal for the MPT system, the frequency and power of signal are controlled by programming on development platform Labview, and the power of signal is calibrated with spectrum analyzer.

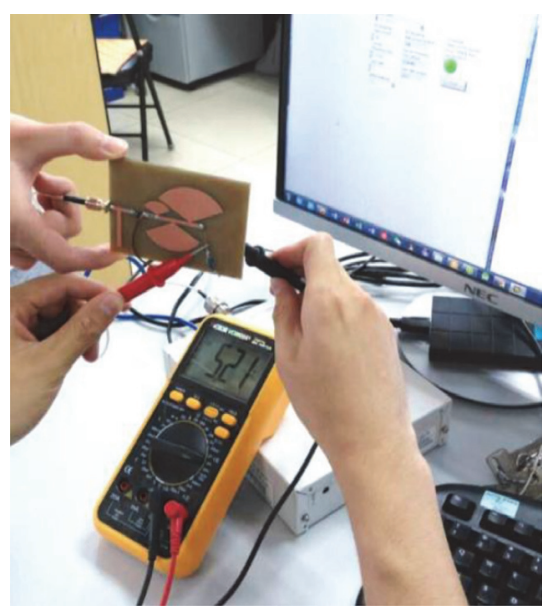

FIGURE 16: Experiment to validate the performance of proposed system.

TABLE 2: Comparison of conversion efficiency of different rectennas.

\begin{tabular}{lc}
\hline Rectenna structure & Max conversion efficiency \\
\hline$[8]$ & $65.2 \%$ \\
[17] with dual patch & $70 \%$ \\
[17] with 6-patch array or 16-patch array & $74 \%$ \\
{$[18]$} & $37.1 \%$ \\
{$[19]$} & $70 \%$ \\
This work & $75.5 \%$ \\
\hline
\end{tabular}

\section{Conclusions}

A high efficiency circular polarization rectenna with features of out-of-band suppression has been proposed for microwave power transfer system. The rectenna is in $150 \mathrm{~mm} \times 55 \mathrm{~mm}$ overall size printed on $1.5 \mathrm{~mm}$ FR4 substrate. $-15.5 \mathrm{~dB}$, $-18.1 \mathrm{~dB}$, and $-11.4 \mathrm{~dB}$ depressions on 2 nd to 4 th harmonic frequency band, respectively, are achieved. After harmonic suppression, the antenna shows a flat $S_{11}$ curve up to $-3 \mathrm{~dB}$ in overall out-of-band. By integrating with SBS, the proposed rectenna can achieve $75.5 \%$ RF-to-DC conversion efficiency with $19 \mathrm{dBm}$ input signal power. The conversion efficiency keeps higher than $63 \%$ during input power ranging from $10 \mathrm{dBm}$ to $19 \mathrm{dBm}$.

The proposed rectenna can widely be applied in small size electronic devices, which can significantly enhance the capability for ambient power collection of MPT by avoiding polarization mismatch with linear polarized transmission antenna, and greatly help saving time for charging of battery or bulk capacitor in relative low RF power ambient environments with high RF-to-DC conversion efficiency.

\section{Competing Interests}

The authors declare that there is no conflict of interests regarding the publication of this paper.

\section{Acknowledgments}

This work was supported by National Natural Science Foundation of China (nos. 61427801 and 61601040), National Key Technology Support Program (2014BAK02B05), and Scientific and Research Innovation Program of BUPT (no. 2016RC02).

\section{References}

[1] S. Y. R. Hui, W. Zhong, and C. K. Lee, "A critical review of recent progress in mid-range wireless power transfer," IEEE Transactions on Power Electronics, vol. 29, no. 9, pp. 4500-4511, 2014.

[2] Z. N. Low, R. A. Chinga, R. Tseng, and J. Lin, "Design and test of a high-power high-efficiency loosely coupled planar wireless power transfer system," IEEE Transactions on Industrial Electronics, vol. 56, no. 5, pp. 1801-1812, 2009.

[3] A. Kurs, A. Karalis, R. Moffatt, J. D. Joannopoulos, P. Fisher, and M. Soljačić, "Wireless power transfer via strongly coupled magnetic resonances," Science, vol. 317, no. 5834, pp. 83-86, 2007.

[4] A. P. Sample, D. A. Meyer, and J. R. Smith, "Analysis, experimental results, and range adaptation of magnetically coupled resonators for wireless power transfer," IEEE Transactions on Industrial Electronics, vol. 58, no. 2, pp. 544-554, 2011.

[5] J. O. McSpadden and J. C. Mankins, "Space solar power programs and microwave wireless power transmission technology," IEEE Microwave Magazine, vol. 3, no. 4, pp. 46-57, 2003.

[6] J.-H. Chou, D.-B. Lin, K.-L. Weng, and H.-J. Li, "All polarization receiving rectenna with harmonic rejection property for wireless power transmission," IEEE Transactions on Antennas \& Propagation, vol. 62, no. 10, pp. 5242-5249, 2014.

[7] K. Niotaki, A. Georgiadis, and A. Collado, "Dual-band rectifier based on resistance compression networks," in Proceedings of the IEEE/MTT-S International Microwave Symposium (MTT-S '14), pp. 1-3, 2014.

[8] P. Lu, X. S. Yang, J. L. Li et al., "A compact frequency reconfigurable rectenna for 5.2- and 5.8-ghz wireless power transmission," IEEE Transactions on Power Electronics, vol. 30, no. 11, pp. 6006-6010, 2015.

[9] C. Song, Y. Huang, J. Zhou, J. Zhang, S. Yuan, and P. Carter, "A high-efficiency broadband rectenna for ambient wireless energy 
harvesting," IEEE Transactions on Antennas and Propagation, vol. 63, no. 8, pp. 3486-3495, 2015.

[10] J. A. Hagerty and Z. Popovic, "An experimental and theoretical characterization of a broadband arbitrarily-polarized rectenna array," in Proceedings of the IEEE MTT-S International Microwave Symposium Digest, vol. 3, pp. 1855-1858, Phoenix, Ariz, USA, May 2001.

[11] N. Shinohara and H. Matsumoto, "Experimental study of large rectenna array for microwave energy transmission," IEEE Transactions on Microwave Theory and Techniques, vol. 46, no. 3, pp. 261-268, 1998.

[12] C.-Y. D. Sim, M.-H. Chang, and B.-Y. Chen, "Microstrip-fed ring slot antenna design with wideband harmonic suppression," IEEE Transactions on Antennas \& Propagation, vol. 62, no. 9, pp. 4828-4832, 2014.

[13] R. A. Rahim, S. I. S. Hassan, F. Malek et al., "A $2.45 \mathrm{GHz}$ circular patch antenna with harmonic suppression for wireless power transmission," in Proceedings of the IEEE Colloquium on Humanities, Science and Engineering (CHUSER '12), pp. 283287, December 2012.

[14] R. A. Rahim, F. Malek, M. F. Jamlos, S. I. S. Hassan, M. N. Junita, and M. N. Azizan, "A $2.45 \mathrm{GHz}$ harmonic suppression rectangular patch antenna," in Proceedings of the IEEE Symposium on Computer Applications and Industrial Electronics (ISCAIE '12), pp. 242-246, IEEE, Kota Kinabalu, Malaysia, December 2012.

[15] F.-J. Huang, T.-C. Yo, C.-M. Lee, and C.-H. Luo, "Design of circular polarization antenna with harmonic suppression for rectenna application," IEEE Antennas \& Wireless Propagation Letters, vol. 11, pp. 592-595, 2012.

[16] HSMS-286x Series, Surface Mount Microwave Schottky Detector Diodes Data Sheet.

[17] Y.-J. Ren and K. Chang, "5.8-GHz circularly polarized dualdiode rectenna and rectenna array for microwave power transmission," IEEE Transactions on Microwave Theory and Techniques, vol. 54, no. 4, pp. 1495-1502, 2006.

[18] T. Matsunaga, E. Nishiyama, and I. Toyoda, “5.8-GHz stacked differential mode rectenna suitable for large-scale rectenna arrays," in Proceedings of the 3rd Asia-Pacific Microwave Conference (APMC '13), pp. 1200-1202, Seoul, South Korea, November 2013.

[19] J. Zhang, Z. P. Wu, C. G. Liu, B. H. Zhang, and B. Zhang, "A double-sided rectenna design for RF energy harvesting," in Proceedings of the IEEE International Wireless Symposium (IWS '15), pp. 1-4, IEEE, Shenzhen, China, April 2015. 


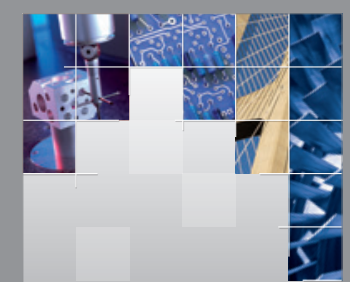

\section{Enfincering}
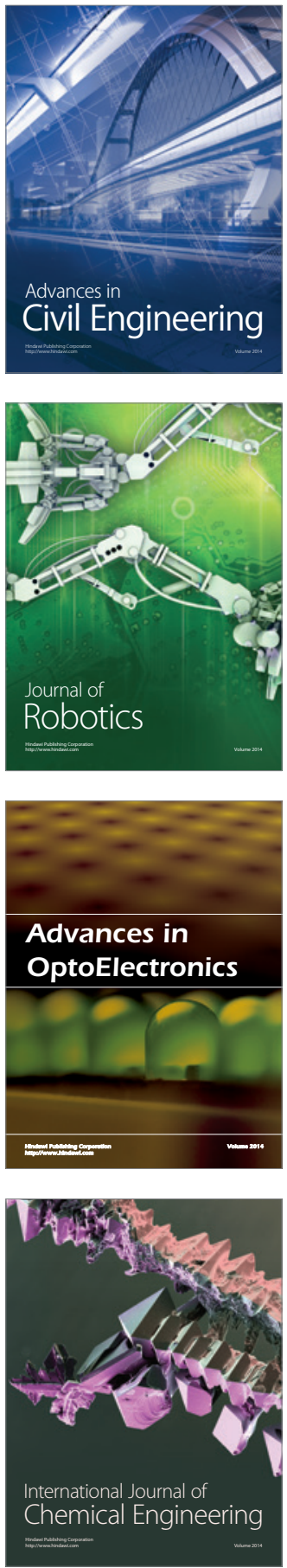

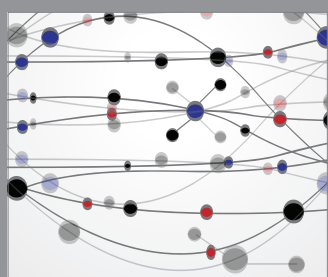

The Scientific World Journal

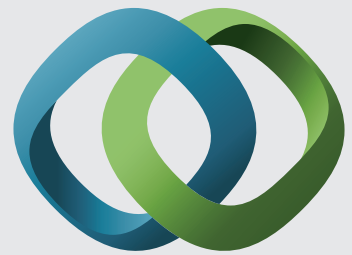

\section{Hindawi}

Submit your manuscripts at

http://www.hindawi.com
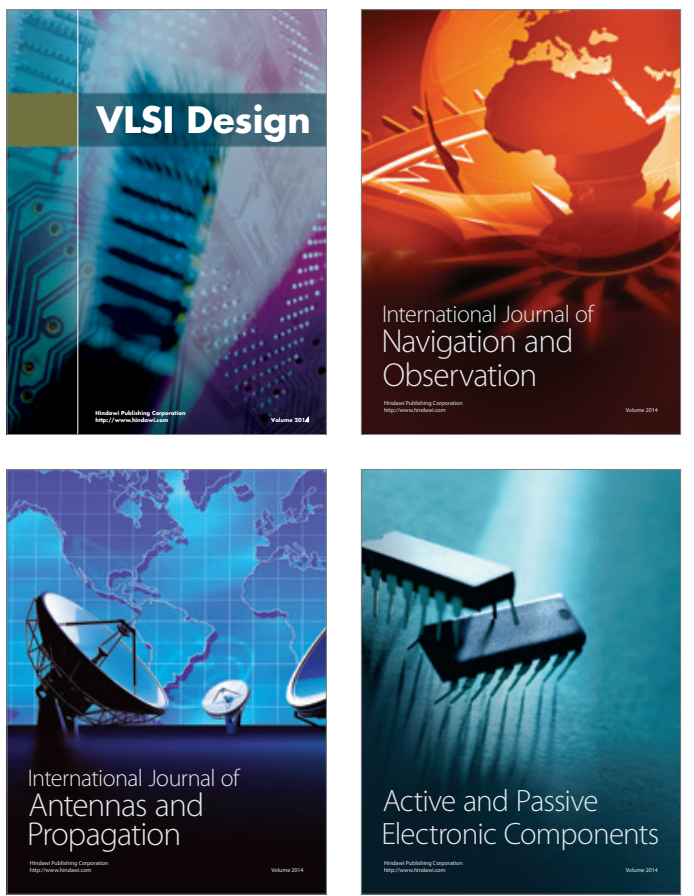
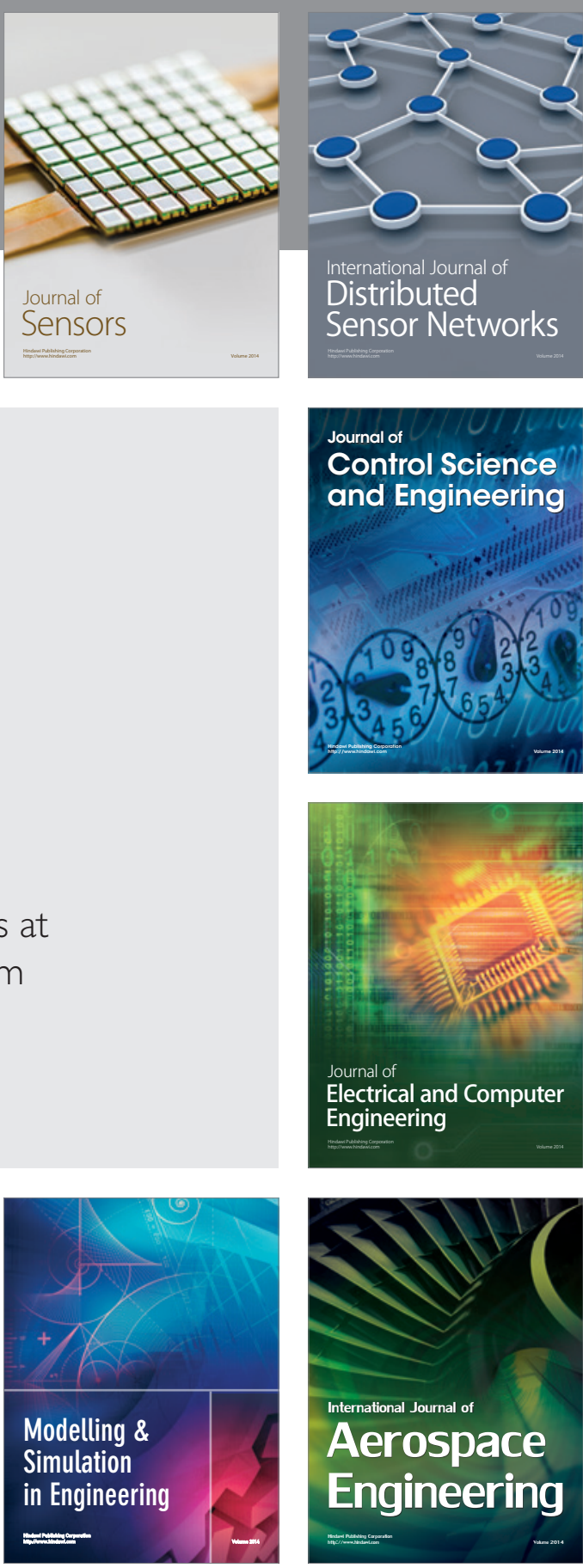

International Journal of

Distributed

Sensor Networks

Journal of

Control Science

and Engineering
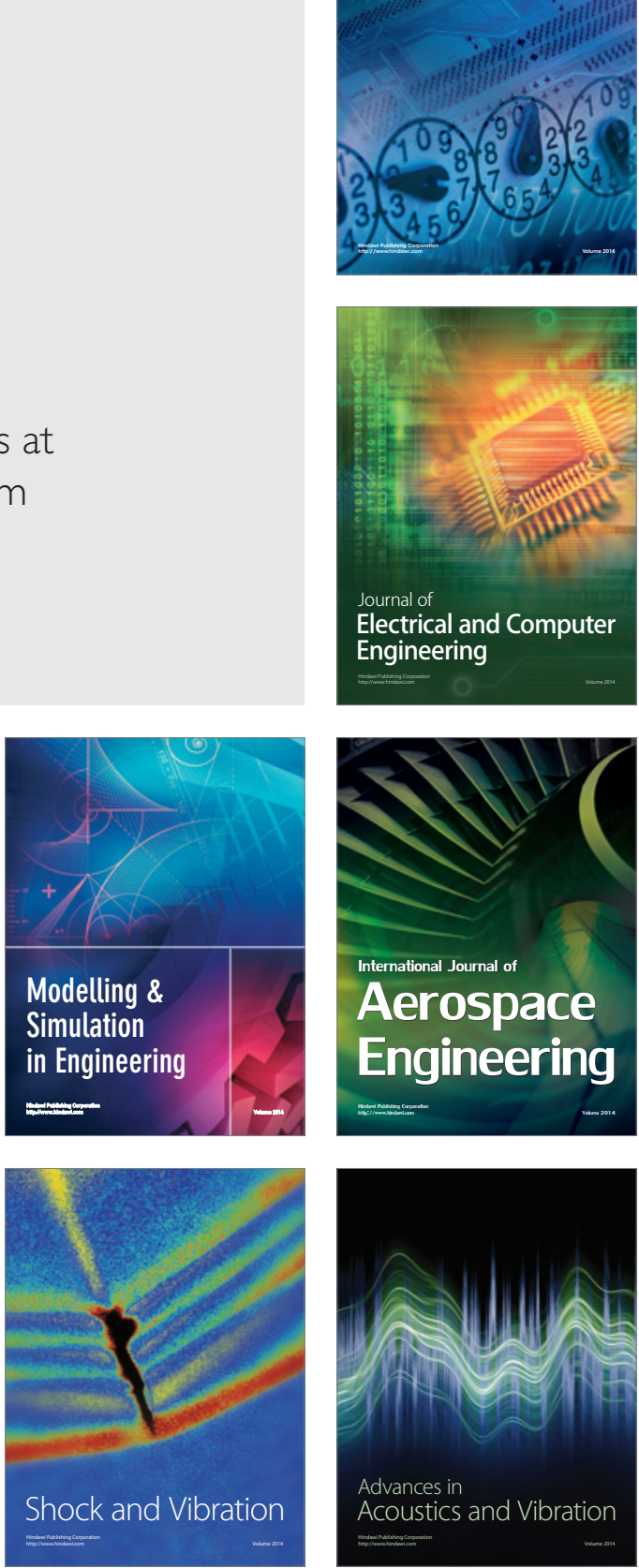